\title{
Las nodrizas afrodescendientes en el Nuevo Reino de Granada siglo XVII: valor cultural y \\ científico
}

\begin{abstract}
Afro-descendant wet-nurses in the New Kingdom of Granada in seventeenth century: Cultural and scientific value
\end{abstract}

DOI: https://doi.org/10.25100/hye.v16i54.9884

Artículo recibido: 31-05-2019- Artículo aceptado: 10-01-2020

\section{María Cristina Navarrete Peláez}

Cursó Historia en la Facultad de Humanidades, Universidad del Valle. Realizó estudios de doctorado en la Universidad Complutense de Madrid y su tesis Esclavitud Negra e Inquisición. Los negros en Colombia. 1600-1725, mereció la calificación de Sobresaliente Cum Laude. También posee una maestría en educación realizada en City College de Nueva York (CUNY). Ha dedicado su vida profesional a la enseñanza en la Universidad del Valle como profesora titular y a la investigación histórica en aspectos étnicos, específicamente la participación de la población afrodescendiente en Colombia, siglos XVI y XVII. Actualmente se dedica a investigar sobre los movimientos de resistencia de los cimarrones en el Caribe colombiano. El presente artículo es uno de los resultados de una investigación más amplia sobre la esclavización iniciado hace varios años.

Universidad del Valle, Colombia.

Correo electrónico: mcmanavarr @gmail.com

ORCID: 0000-000211-4105

Forma de citar este artículo: Navarrete Peláez, María Cristina. "Las nodrizas afrodescendientes en el Nuevo Reino de Granada siglo XVII: valor cultural y científico". Historia y Espacio, vol. 16 n 54 (2020): 27-46. Doi.org/10.25100/hye.v16i54.9884.

Artículo Tipo 2: de reflexión 


\section{Resumen}

El artículo busca resaltar el papel de la mujer afrodescendiente en el siglo XVII, en el Nuevo Reino de Granada, especialmente el de las nodrizas. Las familias de élite y de grupos pudientes alquilaban amas de cría para la lactancia de sus hijos recién nacidos. También aprovechaban alguna de las esclavas domésticas que hubiera parido recientemente. Se intenta demostrar el papel de mediadoras culturales que desempeñaron las nodrizas en la crianza de estos infantes. Evidencia, por medio de estudios recientes, el valor científico de la lactancia que sin duda repercutió en la defensa de enfermedades en los siglos coloniales.

Palabras clave: ama de cría, lactancia materna, mediador cultural.

\section{Abstract}

The article seeks to highlight the role of women of African descent in seventeenth century, in the New Kingdom of Granada, especially that of wet- nurses. Elite families and wealthy families rented nursing mothers for the nursing of their newborn children. They also took advantage of some of the domestic slaves that had recently given birth. The article also attempts to demonstrate the role of cultural mediators played by wet nurses in the upbringing of these infants. Current evidence proves the scientific value of breastfeeding. Recent studies show that breastfeeding contributed to the defense against disease in the colonial centuries.

Keywords: nurse, breast-feeding, cultural mediator. 


\section{Las nodrizas afrodescendientes en el Nuevo Reino de Granada siglo XVII: valor cultural y científico}

\section{Introducción}

Es poco lo que se ha escrito sobre la mujer en el período colonial y, todavía menos, sobre la mujer de ascendencia africana. Su papel dista de ser pasivo y la vemos actuar en distintos aspectos de la vida en la Colonia. Como integrante de la sociedad adquirió un papel histórico. Conocedora de plantas, hierbas y raíces, desempeñó el papel de curandera ante la escasez e ineficacia de la medicina tradicional. Algunas eran expertas en aliviar males del alma con sus conjuros y envoltorios mágicos. Junto al hombre negro, libre o esclavizado, hizo posible el desarrollo económico de las regiones y supo aprovechar los resquicios que le dejó la esclavización para demostrar su liberación interior y su potencial creador, no obstante su condición social inferior.

La presencia de esclavizadas, negras y mulatas, tuvo especial significación en los servicios domésticos. En la residencia señorial urbana y en las haciendas del Nuevo Reino de Granada estuvieron a cargo del cuidado de los hijos de la señora y de los propios. Eran las encargadas de cocinar, lavar la ropa, almidonarla, coserla, ordenar las recámaras, y la más responsable de ellas tenía a su cargo "gobernar" la casa y portar las llaves. En ocasiones salían a las calles de la ciudad a vender productos como dulces, chocolate, bollos y frutas. El mayor o menor número de esclavos domésticos se convirtió en una de las formas como las grandes familias de la época obtenían reconocimiento social y hacían explícitas las relaciones de poder patriarcal sobre los esclavizados que les servían.

Las mujeres negras y mulatas libres gozaron de un mayor grado de movilidad; así como las del servicio doméstico, tenían la posibilidad de recorrer las calles de la ciudad y llevar afuera una vida más activa, diferente al reclutamiento que padecían las señoras de alcurnia. Como dice Asunción Lavrin al referirse a la mujer colonial mexicana, una verdadera dama se quedaba en casa ${ }^{1}$.

Muchos esclavizados domésticos eran tomados en alquiler por otros vecinos que requerían sus servicios en diferentes oficios y devengaban un jornal. Jornal

1 Asunción Lavrin, "Investigación sobre la mujer de la colonia en México: siglos XVII y XVIII", en Las mujeres latinoamericanas ( México: Fondo de Cultura Económica, 1985), 64. 
que era entregado al propietario, quien les dejaba un remanente que ahorraban para cubrir necesidades y particularmente para comprar su libertad. Si la mujer de $\operatorname{castas}^{2}$, mulata o negra, gozaba de libertad, el jornal obtenido era propio de donde derivaba su sustento. No obstante, esta libertad no le garantizaba una alteración sustantiva en su estrato social.

Es propósito de este artículo resaltar el valor en el aspecto cultural de las nodrizas o "amas de cría", como eran llamadas en el siglo XVII. También, distinguir las diversas visiones que tenían los letrados, jurisconsultos y médicos sobre el acto de amamantar que hicieran la madre o la nodriza, frente a la cotidianidad que se vivía en ese entonces. Del mismo modo, comprender, desde los aportes de los actuales conocimientos médicos, la importancia de la labor de las amas de leche en tiempos coloniales. Se encuadra en el contexto de lo que la historia conoce como transmisión de una tradición y que, según Peter Burke, es un proceso de continua creación. Como se verá, la importancia de que la madre amamante a su hijo, que ha resurgido en la época contemporánea, es como dice el mismo autor el "proceso de traspasar una cultura a una nueva generación”, lo que para él consiste en un proceso de reconstrucción ${ }^{3}$.

Este artículo tiene en cuenta, desde lo metodológico, el campo de la microhistoria entendida como un género específico de narrativa y forma de hacer historia, siguiendo las ideas de Ronaldo Vainfas ${ }^{4}$. Quien sostiene que el objeto de la microhistoria no se encuentra en las estructuras ni en los mecanismos que rigen, fuera de todo subjetivismo, las relaciones sociales, como sí la racionalidad y las estrategias que ponen en funcionamiento las comunidades, las parentelas, las familias y los individuos, según lo que afirma Roger Chartier $^{5}$.

A su vez, acoge la reflexión de Giovanni Levi sobre la necesidad de valorar las condiciones de la realidad de la gente ignoradas por los estudios de grandes dimensiones. Como bien lo dice el autor, el asunto menos investigado son

2 El término casta era sinónimo de color. Grupo de origen o nación africana. También fue usado para significar el resultante del cruce de español con indígena o africano y todos sus mestizos.

3 Peter Burke, ¿Qué es la historia cultural? (Barcelona: Paidós, 2006), 125-126.

4 Ronaldo Vainfas, "De la historia de las mentalidades a la historia cultural", Anuario Colombiano de Historia Social y de la Cultura, N. 23 (1996): 221.

5 Ibíd.,.221-222. Roger Chartier, “L'Histoire aujourd'hui' : doutes, défies, propositions”. Conferencia pronunciada en la Fundación Getulio Vargas, mimeo, 1993. 
las relaciones interpersonales que sin duda contribuyen a determinar las estructuras y la realidad del contexto ${ }^{6}$.

El artículo propone, a la manera de Levi, el estudio de casos escasamente considerados por el historiador; por ello, el presente ensayo se fundamenta en un documento expedido por el tribunal de la Inquisición de Cartagena en 1650. Se trata de un pleito civil entre Diego Fernández de Amaya y Ambrosio Arias de Aguilera por la posesión de una nodriza y se apoya en información que aportan otros documentos con ejemplos de amas de crianza ${ }^{7}$.

La importancia de este documento radica en recoger elementos que se encuentran dispersos en las fuentes documentales del tribunal de la Inquisición ${ }^{8}$ y permite estudiar un aspecto inherente a la naturaleza humana, la lactancia materna. Con ello se intenta escribir un relato de carácter histórico que muestre las interacciones entre los distintos grupos sociales.

Quien escribe se planteó la disyuntiva de cómo presentar los resultados del material recogido en las fuentes e identificar un puente entre el discurso del historiador y la comprensión de quien lee. Además, encontrar una narrativa seria en sus planteamientos, pero agradable al lector. Como propone Levi, esta idea acoge una de las proposiciones de la microhistoria que selecciona una forma de comunicación que concibe al lector como receptor activo y capaz de comprender los significados de la narración?.

\section{Pensamiento y realidad de la lactancia materna en tiempos coloniales}

Durante el período colonial, la costumbre de las amas de cría se utilizó en el Nuevo Reino de Granada con ideas semejantes a las españolas. El uso de amas de leche para la crianza de los infantes fue una práctica muy extendida desde los inicios de la Colonia.

6 Giovanni Levi, “Un problema de escala”, Relaciones, estudios de historia y sociedad vol. XXIV, N. ${ }^{\circ} 95$ (2003): 279-280.

7 El documento se encuentra en el Archivo Histórico Nacional de Madrid (en adelante AHNM) sección de Inquisición, legajo 1611, No. 8. No se estudia la totalidad del documento porque no viene al caso. Como se trata de un juicio hay declaraciones de testigos de cada una de las partes, además, en el pleito se involucran otras desavenencias entre los contendores.

8 El tribunal del Santo Oficio fue instalado en Cartagena en 1610.

9 Giovanni Levi, "Un problema de escala”, Relaciones, estudios de historia y sociedad vol: XXIV, N. 95 (2003): 287. 
En el Nuevo Reino de Granada, las negras y mulatas cumplían el rol de amas de leche y se dedicaban a la crianza de los niños en sus primeros años. Fue una costumbre generalizada que se mantuvo durante el siglo XVII ${ }^{10}$.

En España, el empleo de amas de cría o nodrizas y la práctica de enviar a los infantes a las aldeas al cuidado de familias eran hábitos aceptados por familias aristocráticas o de buena posición económica. La utilización de nodrizas estuvo vigente hasta el siglo XIX ${ }^{11}$.

La costumbre de recurrir a las amas de leche para lactar a los hijos y la idea de que a través de la leche se podían trasmitir características y pensamientos de la mujer que amamantaba datan de tiempos antiguos ${ }^{12}$.

Antonio Olavarrieta resaltaba los prejuicios de esta costumbre. Uno de sus argumentos era que, a través de la leche, las nodrizas, negras y mulatas, transmitían las enfermedades y los vicios de su raza. Esta creencia no era novedosa, puesto que también fue un prejuicio arraigado en España desde el siglo XVI. La madre era la culpable de esta situación al negarse a amamantar a sus hijos prefiriendo que lo realizara una extraña ${ }^{13}$.

Durante los siglos XVI y XVII, se trató de convencer a las madres sobre la importancia de que ellas mismas lactaran y criaran a sus hijos. Esta campaña fue acogida por los humanistas españoles del siglo XVI: Juan Luis Vives, Antonio de Guevara, Pedro Luján y fray Luis de León ${ }^{14}$.

La oposición de fray Luis de León a la lactancia de las amas de leche tiene como fundamento la participación de extraños en la formación moral y social de los hijos. Era parte del discurso de la época de magnificar los beneficios de la leche materna en la formación de los hijos ${ }^{15}$.

${ }^{10}$ Claudia Rosas Lauro, "Educando el bello sexo: la mujer en el discurso ilustrado”, en El Perú en el siglo XVIII, la era borbónica, comp. Scarlett O’Phelan Godoy (Lima: Pontificia Universidad Católica del Perú, Instituto Riva Agüero (1999), 402.

${ }^{11}$ Ibíd., 207-208.

${ }^{12}$ Claudia Rosas Lauro, "La visión ilustrada de las amas de leche negras y mulatas en el ámbito familiar (Lima, siglo XVIII)”. Passeurs, mediadores culturales y agentes de la primeraglobalización en el mundo ibérico, siglos XVI-XIX, eds. Scarlett O'Phelan Godoy y Carmen Salazar-Soler (Lima: Ira-Ifea 2005), 311.

${ }^{13}$ Rosas Lauro, "Educando el bello sexo", 402. Antonio Olavarrieta emite estos argumentos en el Perú colonial.

${ }^{14}$ Olga Rivera, "La leche maternal y el sujeto de los descendientes en la Perfecta casada". Hispanic Review vol. 70, N. ${ }^{\circ} 2$ (2002): 207.

${ }^{15}$ Ibíd., 208. 
Vives y fray Luis querían convencer a las madres de ejercer la lactancia propia con la creencia de que las amas de cría transmitían por medio de la leche vicios, enfermedades, cualidades físicas, emocionales y morales $[. . .]^{16}$ a los recién nacidos."

Por su parte, Julio Caro Baroja afirmaba que en España estas creencias eran postuladas por teólogos, jurisconsultos y médicos que temían la transferencia de ideas religiosas heréticas, al emplear nodrizas moriscas o judías ${ }^{17}$.

En las cortes de Felipe III (1578-1621) y Felipe IV (1605-1665) se prohibió la contratación de amas de leche moriscas, judías o heréticas por temor a la contaminación de ideas no permitidas al lactante. Sin embargo, fue en el siglo XVIII cuando se desató la catilinaria contra el uso de las amas de crianza y una férrea adhesión a favor de la lactancia materna que ocupó un punto central en el discurso de los ilustrados dirigido a las mujeres. Se desarrollaron campañas publicitarias en contra de las nodrizas. Lo discutían los médicos y filósofos en sus tratados ${ }^{18}$.

No obstante el discurso de los teólogos, jurisconsultos y médicos, el quehacer de las amas de cría negras, mulatas e indias continuó en el Nuevo Reino durante todo el siglo XVII. En el ámbito privado del hogar colonial las diatribas de los doctos no tuvieron efecto ${ }^{19}$. La costumbre estaba muy arraigada y los temores de la Ilustración todavía no llegaban con la virulencia que tuvieron en Europa.

Las señoras de alcurnia y las que podían sostener el jornal o el uso de las mujeres esclavizadas todavía no se habían impregnado de los saberes que llegarían con el siglo XVIII, contrarios a la tradición vigente.

\footnotetext{
${ }^{16}$ Ibíd., 209.

${ }^{17}$ Ibíd., 210.

${ }^{18}$ Rosas Lauro, “La visión ilustrada”, 329-330.

${ }^{19}$ Lo propio sucedió en Brasil. Rita Segato explica que, a pesar de la presión de los higienistas para quienes el ama de leche era una terrible transmisora de enfermedades, las madres no se sometieron a los dictámenes de la modernidad médica. Rita Segato, "Edipo negro: colonialidad y forclusión de género y raza”, en La crítica de la colonialidad en ocho ensayos. Y una antropología por demanda (Buenos Aires: Prometeo Editorial, 2013), 183.
} 


\section{Las nodrizas en la mediación cultural ${ }^{20}$}

Como decía el historiador Jaime Jaramillo Uribe en la presentación del libro Hijas, esposas y amantes de la antropóloga e historiadora Susy Bermúdez, la historia había sido escrita por varones de las clases dirigentes. Hasta comienzos del siglo XX, los historiadores confinaron a la mujer al hogar, la familia, la procreación y el cuidado de los hijos. Se la excluyó del proceso histórico. Para que surgiera un nuevo punto de vista sobre el papel de la mujer y de otros grupos sociales en la historia se requirió la aparición de una sociedad diferente con nuevos tipos de mentalidad ${ }^{21}$.

La imagen que se había impuesto de la mujer en tiempos de la Colonia estaba relacionada con el estrato social y su origen étnico. Se discriminaba a las mujeres de "castas" de manera diferente a las mujeres de élite por su condición social y étnica.

Algunas de las mujeres de castas se desempeñaron como comadronas y atendían los partos de sus congéneres. Conocían además el arte de curar males de madre ${ }^{22}$ y preparaban bebedizos de plantas para deshacer embarazos indeseados. Para el nacimiento de una criatura se acudía a la ayuda de mujeres expertas de edad madura y gran experiencia. Si se trataba de mulatas, zambas o negras libres, cobraban por sus servicios. En 1632, la zamba Jerónima, a quien llamaban "la partera", atendía partos. En ese mismo año, Juana Hernández, zamba, se sostenía lavando ropa, curando males de madre y parteando. En 1634, Francisca García, mulata, cobró seis pesos por curar un mal de madre. Por esta época también era reconocida como experimentada partera, Jerónima, negra horra $^{23}$, nacida en Sevilla y, en 1636, Elena de Viloria, negra libre soltera, realizaba con éxito el oficio de partera ${ }^{24}$.

Como explica Asunción Lavrin, falta mucho por explorar de las vidas de las mulatas libres y de las pertenecientes a las castas. La libertad de la que

${ }^{20}$ En este caso, se entiende por mediación cultural la interacción social del infante (el bebé amamantado) con personas significantes en su vida (la nodriza) mediante las cuales construye conocimiento. Lo cual sucedió a pesar de que los sujetos no pertenecían a la misma categoría social.

${ }^{21}$ Jaime Jaramillo Uribe, Presentación de Hijas, esposas y amantes, por Susy Bermúdez (Bogotá: Ediciones Uniandes, 1983), 5-7.

${ }^{22}$ Es posible que curar males de madre se refiriese al cuidado después del parto o de quienes abortaban.

${ }^{23}$ Ahorrío era el hecho de conseguir la libertad. Horro era el esclavizado que obtenía la libertad.

${ }^{24}$ Relaciones de causas de fe, AHNM, Inquisición, Legajo 1022 y Libro 4822. 
gozaban les permitió un mayor grado de movilidad, variedad de oficios y una posición social diferente. Constituyeron un elemento necesario en el trabajo de ciudades y áreas rurales ${ }^{25}$.

El 22 de junio de 1651, ante don Esteban Márquez, alcalde ordinario de Cartagena, se presentó Ana Fernández, morena, para hacer una petición. Tuvo noticias de que en el testamento y renuncia de bienes que realizó doña Isabel Jiménez antes de internarse en el convento de Santa Clara incluyó una cláusula a favor de su libertad. En virtud de tal testimonio, el señor alcalde solicitó la expedición del documento que acreditara su derecho a la libertad. En conformidad con lo antes expresado el señor alcalde ordenó al escribano don Martín de Escobar Ibáñez, escribano público y de gobernación, autorizar en forma pública y dar fe de la dicha cláusula para que en justicia Ana obtuviera su carta de libertad ${ }^{26}$.

En el testamento que realizó doña Isabel Jiménez en el convento de Santa Clara el 17 de febrero de 1650 expresa que, de la venta de sus bienes se disponga la cantidad necesaria para el ahorrío de Ana, morena criolla, esclava que heredó de su padre por el amor y voluntad que le tengo por haberme criado y, en concordancia, se le otorgue escritura de libertad ${ }^{27}$.

Hacía unos veinte años, Ambrosio Arias de Aguilera, vecino de Cartagena, se dirigió a la casa donde habitaba Diego Fernández para pedirle en alquiler o compra una esclava suya llamada Ana a quien un mulatillo recién parido se le había muerto. Acordaron el negocio y Ana fue trasladada, junto con una hija mulata de nombre María que tenía unos tres años, a la residencia de Ambrosio Arias de Aguilera con la intención de alimentar al pecho a una hija que había nacido de su mujer Ana María Jiménez ${ }^{28}$.

Doña Ana María Jiménez estando en artículo mortis le dijo a su hermana que para el descargo de su conciencia declaraba que la dicha negra Ana criolla y sus hijos le habían servido muy bien y que era su voluntad que no la pudiese vender a nadie después de su muerte porque su voluntad era que sirviera a sus hijos y al dicho

${ }^{25}$ Asunción Lavrin, "La mujer en la sociedad colonial hispanoamericana”, en Historia de América Latina, Vol. 4 (Barcelona: Editorial Crítica, 1990), 135.

26 "Pleito entre Diego Fernández de Amaya y Ambrosio Arias de Aguilera” (Cartagena 1651) AHNM, Inquisición, Asuntos civiles, Legajo 1611, No. 8, folios 51-54.

27 "Pleito entre Diego Fernández de Amaya y Ambrosio Arias de Aguilera”, fls. 51-54.

${ }^{28}$ Se trata de un pleito que tuvieron Diego Fernández de Amaya y Ambrosio Arias de Aguilera sobre la tenencia de Ana criolla y sus hijos y otros negocios en los que no se pusieron de acuerdo los contendores. 
sumarido... ${ }^{29}$. La mujer de Arias tenía por razón de estado el que negra que hubiese criado hija suya al pecho no había de ser esclava de otra persona... ${ }^{30}$.

Ana, después de criar a la niña, estuvo sirviendo de cocinera, costurera, lavandera y en otros menesteres; era mujer de mucho cuidado para el gobierno de una casa y de un enfermo. María, su hija, era aprendiz de costurera. Además, en casa de Ambrosio Arias, parió varios hijos, Luis y Nicolás. Es posible observar las redes sociales que se tejieron entre la familia del infante que estaba siendo amamantado y la nodriza que desempeñaba esa función. Estas relaciones se extendían entre los niños que se criaban juntos y el resto de personas que habitaban la casa señorial. Sin embargo, estos roles sociales no implicaban un cambio en la estructura de las relaciones del hogar puesto que el estatus de propiedad de Ana, María su hija y sus hermanos, continuaba en condiciones de desigualdad, vale decir como esclavizados.

Fue una costumbre habitual entre las familias prestantes del Nuevo Reino conseguir amas de cría para amamantar a los recién nacidos. Pero no podía ser cualquier leche. Para el caso anterior, los esposos Arias y Jiménez fue llamado Diego López, mulato cirujano para que examinase la leche de Ana y conceptuó que era buena ${ }^{31}$.

Así como el servicio de un ama de leche libre, negra o mulata, era altamente gratificado, también el hecho de infringir los requisitos de buena salud era severamente castigado. A mediados del siglo XVII, en Santa Fe de Bogotá, Luisa, una esclava negra de la casa del capitán Diego López de Melgar, que por esos días amamantaba a su hijo recién nacido, tomó bebedizos para abortar al darse cuenta de que había quedado de nuevo embarazada y ocultó el incidente a sus amos; como el infante comenzó a perder peso poniendo su vida en peligro,

29 “Pleito entre Diego Fernández de Amaya y Ambrosio Arias de Aguilera”, fls. 110-114v.

${ }^{30} \mathrm{Ibíd}$., fls. 82v-87v. Uno de los testigos corrobora la versión, se la dio un mulatillo hijo de Ana a quien llaman Chaco.

${ }^{31}$ Ibíd., fls. 87v-91v. Diego López, mulato cirujano, era llamado con frecuencia a la casa de Ambrosio Arias para asistir y curar a los enfermos. Conceptuó que el jornal de Ana debía ser de ocho pesos como se acostumbraba en esa época. En cuanto a las nodrizas, cabe recordar lo que expresaba Gabriel García Márquez en su libro Del amor y otros demonios:

La niña, hija de noble y plebeya, tuvo una infancia de expósita. La odió desde que le dio de mamar por la única vez, y se negó a tenerla con ella por temor de matarla. Dominga de Adviento la amamantó, la bautizó en Cristo y la consagró a Olokún, una deidad yoruba de sexo incierto...

Tomado de María Cristina Navarrete, "La mujer negra mediadora de vida y de cultura”, Tzintzun, revista de estudios históricos, N. 22 (1995): 186. 
la madre del niño resolvió venderla como castigo, a pesar del afecto que le tenía por haberse criado juntas. Sin medir las consecuencias, Luisa tomó un bebedizo hecho de altamisa y arracada y aunque no mal parió con el veneno y la preñez puso en riesgo la vida del niño que criaba y el de la criatura que tenía en el vientre ${ }^{32}$.

Las mujeres esclavizadas que desempeñaban labores domésticas, y entre ellas las nodrizas, asumieron la condición de mediadoras entre el mundo de los españoles y criollos y la gente de castas. Fue así como se pusieron en circulación aspectos culturales y saberes que, en su proceso de intercambio, se convirtieron en elementos culturales compartidos.

El tipo de relación que se estableció entre las señoras, los pequeños hijos y las amas de cría se movía en el plano de lo afectivo y lo cultural. Entre ellos se desarrollaron lazos de afecto que en cierta medida privilegiaron la posición de estas esclavas en el ambiente familiar. En muchas ocasiones estas negras y mulatas debían criar paralelamente a dos infantes, situación que implicó que el hijo de la esclava y el de su ama crecieran, se desarrollaran y compartieran juntos los juegos, los comportamientos y las experiencias. En consecuencia, las diferencias de origen en esta primera infancia serían imperceptibles ${ }^{33}$.

Si bien algunas nodrizas consiguieron la libertad y la de sus hijos, en ocasiones estaba condicionada y era restringida. Aun cuando la libertad cambiaba las condiciones de vida de las mujeres afrodescendientes, no obstaba que su estatus social mejorara considerablemente. La libertad suponía ciertas responsabilidades con la familia hasta un determinado tiempo establecido por la propietaria. Es el caso de Ana, quien debía servirle a ella y a su marido hasta su fallecimiento. Era una forma de retener al esclavizado, pero con la esperanza de lograr su libertad. Esta situación muestra que, a pesar de la promesa de libertad, las condiciones de poder y dominación del propietario sobre el esclavizado persistían con los descendientes.

En la sociedad neogranadina del siglo XVII, cuando el índice de mortalidad infantil era elevado, las élites tuvieron que acudir, como forma de suplemento a la leche materna o para suplir su falta, al pecho de jóvenes negras y mulatas

32 “Doña Tomasa de Guzmán contra Diego López de Melgar familiar del Santo Oficio sobre la venta de dos esclavas que éste le vendió" (Cartagena 1657), AHNM, Inquisición, Asuntos civiles, Legajo 1612, No. 20, fls. 43v-49v. Este ejemplo muestra las relaciones de poder y opresión que se ejercieron sobre la esclava Luisa vendiéndola a otra persona como castigo.

${ }^{33}$ Ibíd., 184. Para más información puede consultarse el artículo de María Cristina Navarrete. 
que recientemente habían dado a luz para compartir la leche de su pequeño hijo con el hijo de la señora que la contrataba. Su oficio era altamente remunerado en comparación con los jornales de la época. Hacia 1630, era de ocho pesos al mes y, en 1650, de siete pesos.

El hecho de que un ama de cría de castas tomara en sus brazos al niño de la señora de casa implicaba que fuera ella quien daba quizás los primeros y más significativos contactos visuales y corporales al recién nacido. Lo cuidaba físicamente, le cantaba y enseñaba las primeras palabras. Aun cuando era consciente de su condición inferior y de que su vínculo no lo había por sí misma $^{34}$.

Las nodrizas tuvieron una gran influencia en la cultura de la sociedad colonial al transmitir valores y formas de pensar a través del contacto con los infantes que amamantaban. También, se establecieron relaciones de afecto entre las amas de cría y los infantes a su cargo; sus hijos compartieron juegos y espacios, adquirieron las valoraciones del bien y del mal, la práctica del lenguaje y hábitos alimenticios ${ }^{35}$.

Como afirma Carlo Ginzburg, la cultura popular mantiene relaciones con la cultura dominante que se filtra a las clases populares acorde con sus valores $\mathrm{y}$ formas de vida. A su vez elementos de la cultura popular pasan a la cultura erudita. De allí que proponga el concepto de circularidad cultural ${ }^{36}$.

La mujer afrodescendiente distó mucho de ser un agente pasivo de la historia del Nuevo Reino de Granada en el siglo XVII. Su actividad no se limitó a los quehaceres laborales del campo y la ciudad, sino que influyó en la salud de la sociedad colonial como nodriza, aun cuando era consciente de su condición social y étnica desigual frente a las damas de élite.

${ }^{34}$ Rita Segato, tomando ideas del historiador brasileño Luis Felipe Alen Castro, considera que la madre sustituta, esclava o contratada, aunque se envolvía afectivamente con el infante, era consciente de su condición de esclavizada o liberta y de que el vínculo que asumía no lo había tomado por decisión propia. Ibíd., 199

${ }^{35}$ Rigoberto Banguero Velasco al hacer alusión a la vida sexual y familiar de Casa grande y senzala de Gilberto Freire se refiere a la relación del niño esclavista con el ama de leche por medio de canciones de arrullo y de relatos de fantasmas, duendes y de apariciones a los niños que lloraban por la noche. Rigoberto Banguero Velasco, "El esclavo negro en la vida sexual y familiar del brasileño de Casa grande y senzala”, Poligramas, n. 39 (primer semestre 2014): 112.

${ }^{36}$ Ronaldo Vainfas, "De la historia de las mentalidades a la historia cultural”, Anuario Colombiano de Historia Social y de la Cultura, N. 23 (1996): 226. Tomado de Ginzburg. 


\section{Lo que la ciencia dice hoy sobre la leche materna}

Lo expuesto en el acápite "Las nodrizas en la mediación cultural" adquiere vigencia al convertirse la lactancia materna en objeto de estudio científico. El vínculo de la lactancia materna, como función natural del género humano, con la cultura guarda relación con las diferentes formas de abordarla según la temporalidad histórica. Además, tanto la lactancia de la propia madre como la de una sustituta han sido pensadas de manera diferente en distintas temporalidades.

Paulina Brahm y Verónica Valdés, adscritas al departamento de Medicina Familiar de la Pontificia Universidad Católica de Chile, afirman que la lactancia materna es inherente a los mamíferos, entre ellos, al ser humano. Si no hubiera existido, ninguna de las especies habría sobrevivido ${ }^{37}$.

Es importante tener presente que el sexo es una condición biológica que da a la mujer la posibilidad de la procreación, asimismo, la maternidad es una construcción social, no una condición biológica obligatoria; es un hecho natural igualmente construido y representado.

Los primeros meses de vida de un bebé constituyen un período de intenso crecimiento de su cerebro, tal que su masa llega a aumentar el doble durante esta fase crucial. La materia blanca, que es la que conecta las regiones del cerebro y transmite las señales entre ellas, se incrementa notablemente.

La lactancia materna ha comprobado su papel como agente protector contra diversas enfermedades infectocontagiosas, la leucemia y enfermedades inflamatorias del intestino. Además, tiene un impacto positivo en el neurodesarrollo, mejora el coeficiente intelectual y probablemente disminuye el riesgo de condiciones como el déficit de atención y otras alteraciones de la conducta $^{38}$.

Es factible que los padres de familia, urgidos por alimentar a sus recién nacidos, reconocieran empíricamente el valor de la leche materna de nodrizas de castas. La experiencia les habría demostrado que los infantes crecían fuertes y protegidos de enfermedades. Además, la leche materna no sólo suplía las necesidades de alimentación, sino que era más fácil de digerir que la leche de vaca, cabra o la de oveja. Es razonable afirmar que las mujeres de la élite o de familias acomodadas tuvieran conciencia de que la leche de jóvenes negras y mulatas y demás castas podía sustituir la suya. El asunto radicaba en que, en

${ }^{37}$ Paulina Brahm y Verónica Valdés, "Beneficios de la lactancia materna y riesgos de no amamantar", Revista Chilena de Pediatría 1, N. . 88 (2017): 8.

${ }^{38}$ Ibíd., 7. 
una sociedad jerárquica como la del Nuevo Reino de Granada, los mandatarios, los que poseían fortunas y las familias de alto rango no solo eran los dueños del poder, sino que consideraban a los grupos de castas como socialmente subordinados y étnicamente inferiores y podían, por lo tanto, sacar provecho de su condición subalterna.

La alimentación del lactante sólo con leche materna ha comprobado que aminora el riesgo de infecciones gastrointestinales y tiene una consecuencia residual hasta dos meses después de suspender la lactancia: la frecuencia de diarreas dilatadas es menor en lactantes amamantados. En cuanto a las infecciones respiratorias, los infantes lactados durante los primeros seis meses de vida presentan menos mortalidad por neumonía que los niños no amamantados. Por otra parte, los pequeños alimentados con cualquier volumen de leche materna presentan menos riesgo de contraer otitis media aguda. También, tiene el efecto protector de prevenir muertes infantiles ${ }^{39}$.

Además de los factores medibles mencionados, existe un aspecto muy importante y es la repercusión del fuerte vínculo materno-infantil que secrea con la lactancia materna sobre la inmunidad, dado que, durante el parto como durante la lactancia, se suscita un mecanismo neuro-hormonal que influye sobre la inmunidad del bebét ${ }^{40}$.

Las amas de cría, en substitución de la madre, establecieron lazos de afecto entre ellas y el recién nacido. Así mismo, fueron las nodrizas quienes les ofrecieron seguridad, ternura y cariño al perder el contacto directo con las madres.

La leche materna es de fácil digestión, no se descompone ni contamina; el organismo del infante la aprovecha mejor que otro alimento, le brinda cariño, protección, confianza y seguridad al estar en contacto directo con su madre ${ }^{41}$. Investigaciones realizadas en la Universidad de Australia Occidental indican que, si un bebé o su madre se enferman, los componentes protectores de la leche de la madre tienden a aumentar. Es posible que el infante se recupere más rápido, puesto que el cuerpo de la madre creará anticuerpos contra cualquier infección.

\footnotetext{
${ }^{39}$ Ibíd., 8-9 y 11.

40 Juan Ramón Castillo Belén, Alina Rams Veranes, Alexis Castillo Belén, Raúl Rizo Rodríguez y Armando Cádiz Lahens, "Lactancia materna e inmunidad. Impacto social”, Medisan vol. 13, N. ${ }^{\circ} 1$ (Instituto de Ciencias Médicas, Santiago de Cuba, 2009). http://scielo.sld.cu/scielo. php?script=sci_serial\&pid=1029-3019\&lng=es\&nrm=iso. Consultado 15 de abril de 2019.

${ }^{41}$ Ibíd., 3
} 
Además de lo expuesto acerca de la lactancia materna en su aspecto nutricional, en la protección contra diversas enfermedades, en el aumento del bienestar psíquico, es importante destacar la importancia en la estimulación del lenguaje en edad temprana, puesto que sienta las bases para el desarrollo correcto del lenguaje. Una correcta succión y deglución son de vital importancia para el fortalecimiento de la musculatura de los labios y los maxilares y por tanto, para la prevención de alteraciones del lenguaje, al tiempo que contribuye a mantener los dientes en posición adecuada ${ }^{42}$.

Las amas de crianza, negras y mulatas, fueron fundamentales para el desarrollo del lenguaje de los infantes que amamantaban, no sólo por las palabras, las canciones y los arrullos, sino también, como dice la investigación australiana, para el fortalecimiento de la musculatura de los labios y los maxilares.

Después del nacimiento, la leche materna es la adecuada para sostener el nexo inmunológico madre-hijo pues le proporciona elementos protectores como células y factores solubles ausentes en el recién nacido. El amamantamiento es el único período en que el ser humano recibe los nutrientes necesarios aptos para las características de inmadurez funcional de los sistemas digestivo, renal e inmunológico del neonato.

La leche humana es el alimento ideal para el infante; es una emulsión de grasas en una solución azucarada que contiene carbohidratos, lípidos, proteínas, calcio, fósforo, vitaminas, células, lactoferrina, cloro, sodio y otras sustancias ${ }^{43}$.

Si bien los beneficios de la lactancia materna influyen en el bienestar psíquico desde el punto de vista afectivo, el aporte nutricional y el desarrollo posterior de las habilidades para el lenguaje, los autores resaltan el valor importantísimo de su carácter inmunológico ${ }^{44}$.

Estos aspectos llevan a pensar que, en muchas ocasiones, fueron las nodrizas de castas quienes aportaron los beneficios de la leche materna proveyendo a los infantes protección inmunológica, valor nutricional, bienestar emocional y apoyo en el desarrollo del lenguaje en las familias de alcurnia en el Nuevo Reino en el siglo XVII.

\footnotetext{
${ }^{42}$ Ibíd., 3

${ }^{43}$ Ibíd., 2

${ }^{44}$ Ibíd., 5.
} 


\section{Conclusiones}

El papel histórico de la mujer de ancestro afro rebasa los límites de otros agentes. Permitió el crecimiento de la población de sus congéneres al prevenir enfermedades en sus hijos gracias a los nutrientes de la leche materna a pesar de su condición en las esferas bajas de la sociedad.

Contribuyó a la supervivencia tanto de la población criolla blanca como de la mulata, expuestas a diversas enfermedades infectocontagiosas y gastrointestinales.

Tanto los bebés afrodescendientes, como los de otras castas alimentados con leche materna gozaron del impacto positivo en el neurodesarrollo y en el aumento de su intelecto debido, entre otras cosas, a los ácidos grasos que contiene.

Quienes pensaban, en tiempos coloniales, que los africanos y sus descendientes eran "faltos de razón" se sorprenderían al conocer que el cerebro del bebé afro crecía tan rápidamente en los primeros meses de su vida como el de los niños de familias prestantes. Y esto, gracias a las amas de cría que sus padres contrataban para suplir o complementar la leche materna.

También, por la leche suministrada por sus madres, los afros pudieron sobrevivir y reproducirse gracias a los ingredientes vivos, anticuerpos, enzimas y hormonas que les permitieron combatir enfermedades y tener un desarrollo normal. Sin embargo, fueron discriminados social y étnicamente debido a las relaciones de poder y de dominación de los estratos altos.

Fueron las amas de cría quienes dirigieron las primeras palabras al infante a su cargo suscitando el desarrollo del lenguaje, pero así mismo producían efectos de mediación cultural. La voz que escuchaban los infantes era la de su ama de crianza quien les cantaba, sonreía, hablaba y acunaba.

Los lazos de afecto que se constituyeron entre nodriza e infante pudieron repercutir en la constitución de una cultura híbrida y en vínculos afectivos y de dependencia entre la madre del niño y la nodriza. En algunos casos la nodriza y sus hijos consiguieron la libertad, con o sin condiciones. No obstante, ella y sus descendientes afro eran conscientes de que su estatus no ascendía en el aspecto social. 


\section{Referencias bibliográficas}

\section{Fuentes primarias}

Archivo Histórico Nacional de Madrid (AHNM), España.

"Pleito entre Diego Fernández de Amaya y Ambrosio Arias de Aguilera” (Cartagena 1651) AHNM, Inquisición, Asuntos civiles, Legajo 1611, N. ${ }^{\circ} 8$.

"Doña Tomasa de Guzmán contra Diego López de Melgar familiar del Santo Oficio sobre la venta de dos esclavas que éste le vendió" (Cartagena 1657) AHNM, Inquisición, Asuntos civiles, Legajo 1612, N. ${ }^{\circ} 20$.

"Relación de causas de fe" (Cartagena 1632,1634) AHNM, Inquisición, Libro 1022.

"Secuestro de bienes" (Cartagena) AHNM, Inquisición, Legajo 4822.

\section{Fuentes secundarias}

Banguero Velasco, Rigoberto. "El esclavo negro en la vida sexual y familiar del brasileño de: Casa grande y senzala”. Poligramas, 39 (primer semestre 2014).

Brahm, Paulina y Verónica Valdés. "Beneficios de la lactancia materna y riesgos de no amamantar”. Revista Chilena de Pediatría vol. 1, N. ${ }^{\circ} 88$ (2017).

Burke, Peter. ¿Qué es la historia cultural? Barcelona: Paidós, 2006.

Castillo Belén, Juan Ramón et ál. "Lactancia materna e inmunidad. Impacto social”. Medisan vol. 13, N. ${ }^{\circ} 1$ (Instituto de Ciencias Médicas, Santiago de Cuba, 2009). http://scielo.sld.cu/scielo.php?script=sci_serial\&pid=1029-3019\&lng=es\&nrm=iso.[artículo en línea] Consultado 15 de abril de 2019.

Jaramillo Uribe, Jaime. Presentación de Hijas, esposas y amantes, por Susy Bermúdez. Bogotá: Ediciones Uniandes, 1983.

Lavrin, Asunción. "Investigación sobre la mujer de la Colonia en México: siglos XVII y XVIII”. En Las mujeres latinoamericanas. México: Fondo de Cultura Económica, 1985.

Lavrin, Asunción. "La mujer en la sociedad colonial hispanoamericana”. En Historia de América Latina, vol. 4. Barcelona: Editorial Crítica, 1990.

Levi, Giovanni. "Un problema de escala”. Relaciones, estudios de historia y sociedad vol. XXIV, N. ${ }^{\circ} 95$ (2003).

Navarrete, María Cristina. "La mujer negra mediadora de vida y de cultura”. Tzintzun, revista de estudios históricos, N. ${ }^{\circ} 22$ (1995).

Rivera, Olga. "La leche maternal y el sujeto de los descendientes en la Perfecta casada". Hispanic Review vol. 70, N. 2 (2002).

Rosas Lauro, Claudia. "Educando el bello sexo: la mujer en el discurso ilustrado". En El Perú en el siglo XVIII, la era borbónica, compilado por Scarlett O’Phelan Godoy. Lima: Pontificia Universidad Católica del Perú, Instituto Riva Agüero, 1999.

Rosas Lauro, Claudia. "La visión ilustrada de las amas de leche negras y mulatas en el ámbito familiar (Lima, siglo XVIII).” En Passeurs, mediadores culturales y agentes de la primera globalización en el mundo ibérico siglos XVI-XIX, editado por Scarlett O’Phelan Godoy y Carmen Salazar-Soler. Lima: Ira-Ifea, 2005. 
Las nodrizas afrodescendientes en el Nuevo Reino de Granada siglo XVII: valor cultural y científico María Cristina Navarrete Peláez

Segato, Rita. "Edipo negro: colonialidad y forclusión de género y raza”. En La crítica de la colonialidad en ocho ensayos. Y una antropología por demanda. Buenos Aires: Prometeo Editorial, 2013.

Vainfas, Ronaldo. “De la historia de las mentalidades a la historia cultural". Anuario Colombiano de Historia Social y de la Cultura, N. 23 (Bogotá, 1996). 